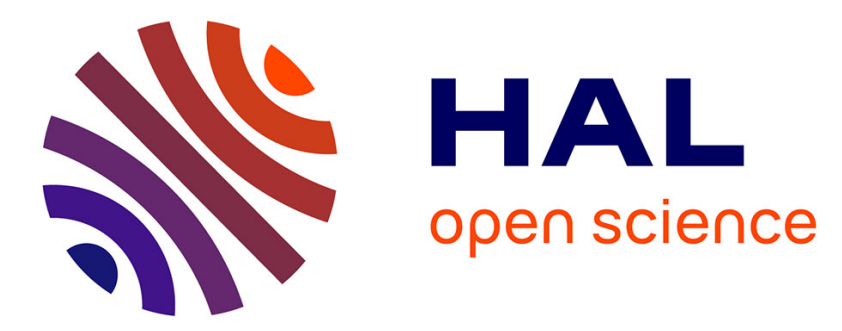

\title{
Multi-Agent Multi-Level Cartographic Generalisation in CartAGen
}

\author{
Adrien Maudet, Guillaume Touya, Cécile Duchêne, Sébastien Picault
}

\section{To cite this version:}

Adrien Maudet, Guillaume Touya, Cécile Duchêne, Sébastien Picault. Multi-Agent Multi-Level Cartographic Generalisation in CartAGen. 12th International Conference on Practical Applications of Agents and Multi-Agent Systems (PAAMS 2014), Jun 2014, Salamanca, Spain. pp.355-358, 10.1007/978-3-319-07551-8_37. hal-01004377

\section{HAL Id: hal-01004377 \\ https://hal.science/hal-01004377}

Submitted on 12 Jul 2017

HAL is a multi-disciplinary open access archive for the deposit and dissemination of scientific research documents, whether they are published or not. The documents may come from teaching and research institutions in France or abroad, or from public or private research centers.
L'archive ouverte pluridisciplinaire HAL, est destinée au dépôt et à la diffusion de documents scientifiques de niveau recherche, publiés ou non, émanant des établissements d'enseignement et de recherche français ou étrangers, des laboratoires publics ou privés. 


\title{
Multi-Agent Multi-Level Cartographic Generalisation in CartAGen
}

\author{
Adrien Maudet ${ }^{1}$, Guillaume Touya ${ }^{1}$, Cécile Duchêne ${ }^{1}$, Sébastien Picault ${ }^{2}$ \\ ${ }^{1}$ Université Paris Est, IGN, laboratoire COGIT, Saint-Mandé, France \\ \{adrien.maudet, guillaume.touya, cecile.duchene\}@ign.fr \\ ${ }^{2}$ LIFL, Université Lille 1, Villeneuve d'Ascq, France \\ sebastien.picaultalifl.fr
}

\begin{abstract}
The objective of cartographic generalisation is to simplify geographic data in order to create legible maps when scale decreases. This demonstration presents the implementation of a work in progress, aiming at defining a multiagent, multi-level solution for generalisation. The demonstration introduces the basics of cartographic generalisation and shows some aspects of the model currently being developed, including parameterisation and detailed execution of some interactions, as well as results.
\end{abstract}

Keywords: Cartography, Cartographic Generalisation, Multi-Level Modelling, Spatialised Problems, Interaction-Oriented Design, Constraints Solving

\section{Introduction}

Generalisation is a process of the cartography domain, aiming at adapting the level of details of geographic objects to a given scale. Different agent-oriented approaches have been used to automate the generalisation process, e.g. [1;2;3;4]. A work in progress [5] aims at enhancing multi-level representation in agent-oriented in order to deal with more complex relation between objects. The proposed model is based on the PADAWAN model [6], initially designed for multi-level simulation, which has been adapted to perform constraint problem solving dedicated to the specific cartographic generalisation application case. In this demonstration, we show an implementation of this model in CartAGen [7], a platform developed and used for research in cartographic generalisation, which is based on the GeOxygen project ${ }^{1}$.

\section{Main purpose}

Geographic information is stored in vector geographic databases, where objects (e.g. buildings, roads) are stored with theirs geometries (e.g. points, polylines, polygons), and attributes (e.g. nature of a building, administrative status of a road). During the

1 http://oxygene-project.sourceforge.net/ 
map creation process, these objects are drawn with given symbols, and depending on the map scale the objects may need to be simplified because room to display the same portion of the real world is smaller at a smaller scale. Modifications need to be done in order to fit the visual perception levels of the final user.

Such readability requirements can be expressed through constraints (e.g. buildings must be above a minimum size, symbols have to be sufficiently spaced). In order to satisfy these constraints, objects may be suppressed, moved, or get their geometry modified, using different algorithms.

The orchestration of these operations is a complex process, because, to generalise one object, other objects, with which constraints may be identified (e.g. a building aligned with others buildings, a road parallel to another road), must be taken into account in order to use appropriate algorithms, with appropriate parameters. In order to automate the generalisation process, agent-oriented solutions were proposed, where geographical objects are described as autonomous agents interacting in order to satisfy its constraints and generalise themselves. Depending on the models, two kinds of interactions are considered:

- Hierarchical interactions (e.g. a building and the urban block, i.e. the portion of space bounded by roads, it belongs to).

- Transversal interactions (e.g. a building with a neighbouring building).

We are developing a model, based on the PADAWAN paradigm, in order to represent interactions and levels used for generalisation in a generic way. PADAWAN is interaction oriented, and interactions are assigned to agents in interactions matrices. In our approach, PADAWAN was modified in order to fit the constraint oriented aspect of generalisation. An agent will evaluate its constraints and choose an interaction to execute. More details on the agent behaviour are given in [5].

\section{Demonstration}

CartAGen is a module of the GeOxygene project, developed in Java at COGIT laboratory. It allows to load, symbolise and display geographical data from various sources, and contains various algorithms to analyse and modify the objects geometries.

In this demonstration, we show the different steps of generalisation using the implementation of our model:

— Loading and symbolising data.

- Creating agents and assign interactions to them in interaction matrices.

- Launching the multi-agent process for a small part of the loaded data.

- Showing the result of generalisation process. 


\section{Conclusion}

This demonstration shows the complexity of the automated cartographic generalisation process. It shows the different steps of a whole generalisation process on a small data set, and a view of some interactions in a detailed way, in order to understand the behaviour of agents. The adapted PADAWAN model is a work in progress, and will be further improved and developed, in order to give solutions for other generalisation issues.

\section{References}

1. Baeijs C., Demazeau Y. and Alvares L.: SIGMA: Application of Multi-Agent Systems to Cartographic Generalization. In: MAAMAW, volume 1038 of Lecture Notes in Computer Science, page 163-176. Springer, (1996)

2. Barrault M., Regnauld N., Duchêne C., Haire K., Baeijs C., Demazeau Y., Hardy P., Mackaness W., Ruas A. and Weibel R.: Integrating Multi-agent, Object-oriented, And Algorithmic Techniques For Improved Automated Map Generalization. In: 20th International Cartographic Conference, vol.3, 2110-2116 (2001).

3. Duchêne C., Ruas A. and Cambier C.: The CartACom model: transforming cartographic features into communicating agents for cartographic generalisation. International Journal of Geographic Information Science, 26(9):1533-1562 (2012)

4. Gaffuri J., Duchêne C. and Ruas A.: Object-field relationships modelling in an agent-based generalisation model. In: Proceedings of 11th ICA workshop on Generalisation and Multiple Representation, Montpellier, France (2008)

5. Maudet A., Touya G., Duchêne C. and Picault S.: Representation of Interactions in a Multi-Level Multi-Agent Model for Cartography Constraint Solving. In: Proceedings of 12th International Conference on Practical Applications of Agents and Multi-Agent Systems, Salamanca, Spain (2014)

6. Picault S. and Mathieu P.: An Interaction-Oriented Model for Multi-Scale Simulation. In: 22nd International Joint Conference on Artificial Intelligence (IJCAI/AAAI), Barcelona, Spain, 332-337 (2011)

7. Renard J., Gaffuri J. and Duchêne C.: Capitalisation problem in research -example of a new platform for generalisation: CartAGen. In: 12th ICA Workshop on Generalisation and Multiple Representation, Zürich, Switzerland (2010) 


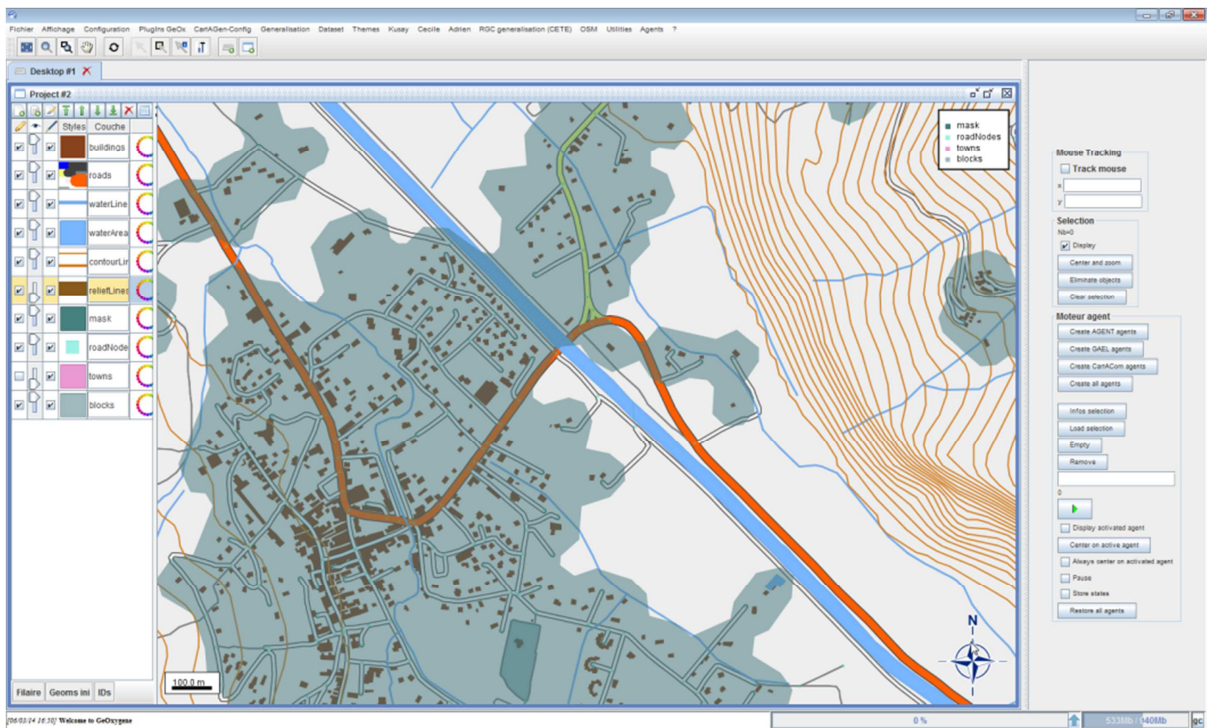

Fig. 1. Screenshot of CartAGen with data loaded.

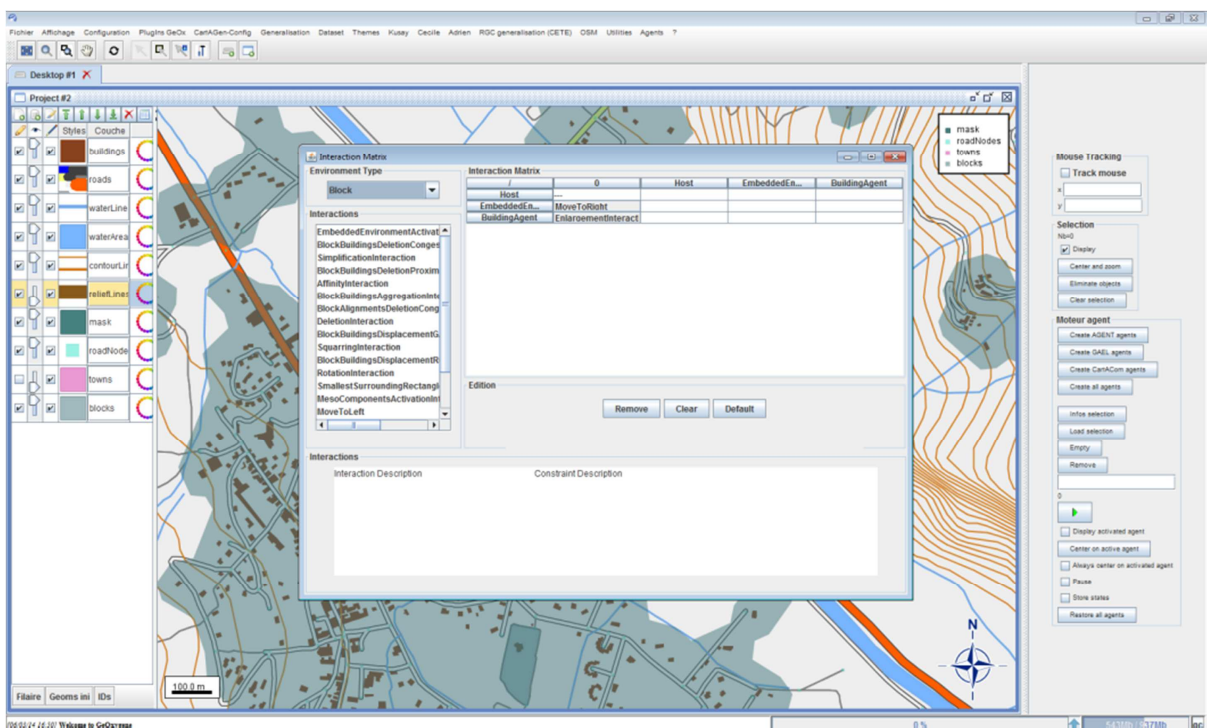

Fig. 2. Screenshot of CartAGen with interactions matrices editor 